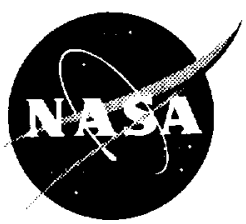

\title{
Analysis of Inlet-Compressor Acoustic Interactions Using Coupled CFD Codes
}

\author{
A. Suresh and S.E. Townsend \\ Dynacs Engineering, Inc., Brook Park, Ohio \\ G.L. Cole, J.W. Slater, and R. Chima \\ Lewis Research Center, Cleveland, Ohio
}

Prepared for the

37th Aerospace Sciences Meeting and Exhibit sponsored by the American Institute for

Aeronautics and Astronautics

Reno, Nevada, January 11-14, 1999

National Aeronautics and

Space Administration

Lewis Research Center 


\section{Acknowledgments}

The authors would like to thank Christopher Miller of NASA Lewis, and Ed Hall of Rolls Royce-Allison for their help with ADPAC, GE Aircraft Engines for making available the T-58 flow path and blade geometries,

Jim Schmidt of Dynacs Engineering for help with the T-58 blade cesign, and Anthony Opalski of the U. Of Cincinnati for filtering the simulation results in the same manner as the experimental data. Funding for this work was provided by the NASA High-Performance Computing and Conmunications (HPCC) Program.

This report contains preliminary

findings, subject to revision as analysis proceed :

Available from

NASA Center for Aerospace Information 7121 Standard Drive

Hanover, MD 21076

Price Code: A03
National Technical Information Service 5285 Port Royal Road Springfield, VA 22100 Price Code: A03 


\title{
ANALYSIS OF INLET-COMPRESSOR ACOUSTIC INTERACTIONS USING COUPLED CFD CODES
}

\author{
A. Suresh", S. E. Townsend" \\ Dynacs Engineering, Inc. \\ NASA Lewis Research Center \\ Cleveland, OH 44135. USA \\ and \\ G. L. Cole $\stackrel{\ddagger}{\ddagger}$ J. W. Slater and R. Chima \\ NASA Lewis Research Center \\ Cleveland, Ohio 44135. USA
}

\begin{abstract}
A problem that arises in the numerical simulation of supersonic inlets is the lack of a suitable boundary condition at the engine lace. In this paper, a coupled approach, in which the inlet computation is coupled dynamically to a turhomachinery computation, is proposed as a means 11 ivercome this problem. The specific application chosen for validation of this approach is the collapsin at the University of Cincinnati. The computed results are found to be in reasonable agreement with experimental results. The coupled simulation results could also be used to aid development of a simplified boundary condition.
\end{abstract}

\section{Introduction}

For high speed supersonic aircraft. mixed-compression engine inlets offer the advantages of high total pressure recovery along with gencrally low total distortion. They are, however, also sensitive 10 atmospheric and engine generated disturbances (such as throttling) which can cause the shock system to he expelled from the inlet. This event, known as an inlet unstart, is generally unacceptable for commercial aircraft such as the high speed civil transport concept.

The ability to predict the unsteady response of such inlets to disturbances is thus useful in the design of such inlets and the active control system used to avoid inlet unstarts. Computational fluid dynamics (CFD) is seeing increased use in this role. While stand alone unsteady inlet simulations ${ }^{1-4}$ can be performed with relative ease. a major uncertainty in these simulations is the boundary condition used at the exit of the inlet (i.e. at the engine lace). A number of houndary conditions have been proposed ${ }^{4-7}$ in the literature to mimic the presence of the engine downstream of the inlet. Figure 1, from reference 6. indicates the importance of using the correct houndary condition since the predicted inlet unstart tolerance to free-stream pressure perturbations can vary hy as much as a factor of six, depending on the brundary condition used.

Computational studies ${ }^{8-11}$ that go beyond simple outflow houndary conditions for the inlet have also been allempled. Using the NPARC code, reflections from a 2D cascade were investigated by Paynter and used to formulate a linearized boundary condition ${ }^{6.7}$. One dimcinsional transient stage by stage models ${ }^{8}$ of whole compressors have also been used to study inlet-engine incractions. The same approach, extended to model an cntirc engine, was coupled to an unsteady 1D inlet code in refierence 9. A similar approach was used by AbdelFultah $^{10}$ to study the effect of total temperature disturbances on the engine compression system. A hybrid approach which combines an axisymmetric inlet simulation with a ID dynamic compressor model, has also been reported by Numbers et. al. ${ }^{11}$

\footnotetext{
* Member AIAA, Research Engineer

Computer Engineer

Member AIAA, Aerospace Engineer
}

This paper is declared a work of the U.S. Government and not subject to copyright protection in the United States. 
An interesting experimental study was conducted ${ }^{12-13}$ to study acoustic reflections from a compressor. In this experiment, a collapsing bump in a constant area annular duct generates an acoustical disturbance of large amplitude. Downstream of the duct is a General Electric T-58 engine in which the combustor has been removed and replaced by a high pressure plenum, which runs the turbine. Reflections of the pulse from this engine are monitored by pressure taps in the duct.

In this paper, we follow a code-coupling approach to study the interaction of inlet disturbances with an engine compressor. The philosophy here is that different components of the engine are best simulated by different specialized CFD codes which are then coupled together using a multi-block approach. We use an existing inlet code (NPARC) ${ }^{14}$ to model the inlet portion of the computation and a turbomachinery code (ADPAC) ${ }^{15}$ to simulate the first stage rotor of an engine compressor. The above mentioned collapsing bump experiment was modeled, and the computed results were compared with experimental results.

\section{Description of Experiment}

The experimental setup is shown schematically in Figure. 2, from reference 13. It consists of a constant area annular inlet duct mated with a GE T-58 engine modified for cold operation. The inlet duct is about 71 inches long and has a screened bellmouth at the upstream end. A small section of the constant area duct has a flexible bump on the hub surface which collapses rapidly to produce well defined acoustic pulses. The length of duct upstream of the bump was chosen so that reflections of the upstream traveling pulse arrive at the observation stations after the time interval of interest.

In our computations, the long inlet duct with the bump was solved using NPARC, a general purpose CFD code capable of handling moving grids. The engine was approximated by its first stage rotor and solved using ADPAC, a turbomachinery code.

\section{Inlet Simulation using NPARC}

Stand alone NPARC simulations of the collapsing bump experiment (with a suitable boundary condition at the engine face) have been carried out previously by Slater et $\mathrm{al}^{16}$. Although the flow in the inlet is axisymmetric, it is solved here as a 3D Euler flow over a sector since the inlet simulation is coupled with a $3 \mathrm{D}$ turbomachinery simulation of an isolated rotor.

The grid for the inlet simulation consists of $186 \mathrm{x}$ $3.3 \times 1.3$ points in the axial. radial and circumferential directic ns respectively. The hub radius and the casing radius are 2.69 and 5.082 inches respectively. The default ADI algorithm in NPARC is used to obtain the referen:e steady state solution. Since the Mach number is quite low, the second order dissipation is set to zero in these computations. For the unsteady computations, a Newton iterative solution which uses iterations of the steady state algorithm are used. This algorithm allows the use of larger time steps; CFL numbers of 50 are typical.

Since trere is some uncertainty in the dimensions of the bump and its dynamics. the height and collapse time of the burnp were chosen to match the experimental pressure profile of the initial downstream traveling pulse. The bump collapses in about 0.85 milliseconds which translates to roughly 340 time steps.

\section{Turbomachinery Simulation using ADPAC}

The firs: stage rotor of the T-58 engine was gridded as a $\mathrm{C}$ grid over one blade passage. A typical mid-span grid $(128 \times 33 \times 33)$ used is shown in Figure 3. For the reference steady solution, the default Runge-Kutta algorithm with 2 levels of multi-grid and residual smoothing were used. The following boundary conditions were used: standard inlet conditions of constant total pressure and temperature at the upstream inlet; no slip conditions (rotating) on the blade and hub surfaces and no slip conditions on the casing; periodic conditions at the azimuthal ends of the blade passage and an exit condition where the static pressure is specified at the hub. This static pressure is not known and is adjusted to achieve the specified mass flow in the inlet duc:

The engine has a variable inlet guide vane (VIGV) to turn the flow so that the engine can be operated efficiently at off-design conditions. The VIGV proved to be mi jor problem as far as the computations were concerne 1. An unsteady simulation of both the guide vane and rotor is essentially a rotor - stator interaction problem requiring considerable computational resources. As a first attempt, we wanted to avoid such complexiy. On the other hand, without the turning offered $b$ r the guide vane, the rotor solution is close to stall anl very different from the experimental condition: This problem was solved in an ad-hoc fashion $b y$ imposing a turning angle on the flow at the rotor inlst. If the axial velocity at the inlet is $u$, a circumfer zntial component $u \tan (s)$, where $s$ is the full metal angle of the VIGV, is added to the velocity vector at the interface. This procedure conserves the mass flow across the interface but not the total energy. A procedure that conserves both mass and total energy can 
be written down but requires an iterative procedure to find the exit state, a complication we wanted to avoid.

As an aside we remark that the guide vane and other stages could possibly be included in the simulation by using a mixing plane approach to transfer average flow properties from one stage to the next.

For the unsteady simulation used during bump collapse, the implicit unsteady algorithm described in the ADPAC manual ${ }^{15}$ was used. This algorithm, which uses an inner pseudo time iteration, was chosen because the time step restrictions of the explicit option are prohibitively expensive. An unsteady non-reflecting condition was also used at the exit boundary since the reflections from the exit boundary are not representative of the experiment.

To achicve faster execution, the ADPAC domain was divided into multiple blocks and run in parallel.

\section{Remarks about Code Coupling}

The basic method used to couple the two codes is very similar to the method used to couple two blocks of a multi-block code. In conventional finite volume codes, a block boundary condition is generally imposed by setting calculated values of the conservation variables at image cells. For coupling two such codes, the procedure used is to simply set the image cells of one code from data obtained from the interior of the other code, as shown in Figure 4. On a theoretical level, if several image cells are used, and data exchanged frequently enough, this approach can couple codes with no loss of accuracy. Even with only a single image cell, the coupled computation can have the same accuracy as current multi-block computations which typically also use only a single image cell.

This simple picture begins to get complicated when we look at coupling the two codes NPARC and ADPAC. Some of the difficulties that arise include the following: 1) NPARC is a finite difference code while ADPAC is a finite volume code; 2) data between blocks is exchanged once every time step in NPARC and every Runge-Kutta stage in ADPAC; 3) the ADPAC code passes gradient information between blocks to more accurately calculate the artificial dissipation terms at block boundaries. These were resolved as follows: (1) an interpolation routine was used to calculate values at the image cell locations (part of VCE, as described in the next section); (2) the ADPAC code was modified so that data was exchanged only every time step at coupled boundaries; (3) this was solved by either setting the artificial dissipation terms to zero at coupled boundaries or recalculating them. With these approximations, the coupled simulations cannot claim to have the same accuracy as multi-block computations. Hence, the accuracy of code coupling was assessed by solving some well known test problems, one of which is described below.

\section{Visual Computing Environment}

The actual mechanics of coupling the two codes was accomplished through the Visual Computing Environment (VCE) $)^{17 \%}$ software developed by CFD Research Corporation. This software consists of a graphical user interface (GUI) and subroutine libraries which provide a means to control the execution of one or more (possibly distributed) codes and the communication between them. Existing VCE flow visualization and 2D plotting codes were used during this study in addition to the VCE enhanced ADPAC and NPARC flow solvers.

Incorporating a code into VCE typically requires some restructuring so that control of the simulation is performed via a VCE script rather than embedded in programmed iteration loops. This generally implies removing the top level control structure and providing wrapper routines to the highest level subroutines. The VCE script is then used to implement an easily modifiable top level control which invokes the wrapper routines.

To couple codes which potentially use different types of grids requires some means of interpolating values from one grid onto another. VCE supplies a library of routines to ease this problem, handling arbitrary combinations of tinite difference, finite volume, and unstructured grids.

To actually run a coupled simulation, the VCE GUI is used to start the various codes and then one or more scripts are run. The scripts typically tell VCE to perform various tasks such as march a time step. exchange interface data with each other. update the viewer with the most recent solution, etc. The VCE scripting language supports most programming constructs, high level communications, and parallel execution of multiple serial or parallel codes.

\footnotetext{
$\$$ The name of this software has since been changed to Multi-Disciplinary Computing Environment (MDICE).
} 


\section{Results}

1. Validation of Code Coupling:

A number of unsteady test problems were solved to assess the accuracy or lack thereof of the coupling procedure used to couple the ADPAC and NPARC codes. One such problem is the well known double Mach reflection problem which features fast-moving strong shocks and contact surfaces which for our solution move obliquely across the coupled-code interface.

The computational domain was split horizontally with the lower portion solved by NPARC and the upper portion solved by ADPAC. The interface of the two codes is at $y=0.22$, which was chosen to lie near the triple point of the solution. A detailed description of the problem and various solutions can be found in Woodward et al ${ }^{18}$.

The coupled solution is shown in Figure 5. A slight thickening of the bow shock can be observed as it crosses the coupled interface. Other than this feature. the solution has the same resolution as a single code solution, with the two Mach stems and the wall jet well resolved.

These results along with several other unsteady test cases demonstrated that the coupled simulations were capable of reasonably accurate results.

\section{The Collapsing Bump Experiment:}

The collapsing bump experiment was run with ADPAC. NPARC, XMGR (a line plotting utility), and CFD_VIEW (a viewer) all coupled through VCE. A snapshot of the monitor screen during a simulation is shown in Figure 6.

A direct comparison of the computational and experimental results is given in Figure 7 , where the change in pressure normalized by its steady state value is plotted against time. Both sets of data were filtered to eliminate frequencies above $2000 \mathrm{~Hz}$. This was done to eliminate engine noise and a $3000 \mathrm{~Hz}$ oscillation. believed to be due to transverse mode oscillations setup by the bump collapse. The oscillation is clearly visible in the station 1 simulation results of Figure 6 beginning at about 0.008 second, and it was in good agreement with the amplitude and frequency of the unfiltered experimental data ${ }^{19}$. The computed and experimental incident waves at stations $1-3$ are in especially good agreement both having the same "peak" amplitude of about -0.038 at all three stations. The results for station 4 were examined in more detail as described below.
Reference 12 stated that the shape of the downstreamtraveling pulse remains essentially constant during propagation. This fact can also be observed from the initial pulse exhibited by each time history at stations 1, 2 and 3 in Figure 7. The initial pulse at station 4, however, is different, both in (minimum) amplitude and shape. This is due to the incident wave overlapping with the wave reflected from the engine. It is the nature of the reflected wave that is of major interest. Reference 12 outlined a procedure for calculating the "net" reflected wave shape at any location by convecting the incident wave to that location and subtracting this from the total pressure wave. The results of this calculation at station 4 are shown in Figure 8. For comparison, reflected waves obtained from the experimental data and from a 1-D simulation of the experiment, using the LAPIN code with a new exit boundary condition ${ }^{6}$ are also shown in Figure 8.

All of the results show the reflected wave to have the same sign as the incident wave (i.e., an expansion wave) but witt amplitudes less than half of the incident wave. The two simulation results are very similar, both having a single "dip" with a pulse width nearly the same as the incident wave, whereas the reflected wave from the experiment has multiple "dips" and is more spread out in time. These multiple dips are probably due to reflections from successive blade rows in the compressor that are not represented in either simulation. It appears that the NPARC-ADPAC (single rotor) simulation does validate the boundary condition used with LAPIN, which is based on a single row cascade analysis. However, it remains to define a figure of merit, stich as unstart tolerance, to measure how well the simulations represent the reflective qualities of the real engi ne.

All coniputations were performed on SGI Power Challenge clusters. Initially NPARC and ADPAC were both run serially, which resulted in an unacceptable execution time of several days. Dividing the ADPAC domain into seven nearly-equal grid blocks resulted in a speedup of about 4.5. Execution time per time step was about $25 \mathrm{sec}$ for ADPAC and $5 \mathrm{sec}$ for NPARC. A typical $r$ in, simulating 10.4 milliseconds, took about 5600 tim $:$ steps and was accomplished in roughly $\mathbf{3 2 . 5}$ hours of slock time. By using 21 blocks in parallel for ADPAC he simulation was reduced to about 12 hours. Since the flow solvers are fairly time consuming, the VCE overhead is very minimal for this case.

\section{Concluding Remarks}

Our investigation indicated that coupling inlet and turbomac hinery CFD codes is a feasible way to study 
inlet-engine interaction problems. However, significant speed up is still required for the method to be useful as a design/analysis tool.

A multi-block coupling approach offers a quick and easy way to couple two CFD codes together. This coupling is flexible enough to be used for steady state and unsteady computations. This approach also offers the possibility of including other specialized codes (e.g. combustor) to provide a full engine simulation.

The computational results gave reasonable agreement with the collapsing bump experiment. The coupled NPARC-ADPAC codes could also serve as a test bed for exploring other flow perturbations of interest, such as convective temperature and tangential velocity disturbances, and for validation of simplified boundary conditions.

Finally, the Visual Computing Environment Software (VCE) offers a nice degree of control over coupled simulations without adding significant overhead to the computation time.

\section{References}

1. Hedges, L., Lewis, J., Carlin, C., and Beck, C., "Supersonic Inlet Simulation with Closed Loop Control and Moving Control Surfaces," AIAA Paper 96-0493, January (1996).

2. Cole, G. L., Melcher, K. J., Chicatelli, A. K., Hartley, T. T., and Chung, J. K., "Computational Methods for HSCT-Inlet Controls/CFD Interdisciplinary Research," AIAA Paper 94-3209, June 1994.

3. Mayer, D. W., and Paynter, G. C., "Prediction of Supersonic Inlet Unstart Caused by Freestream Disturbances," AIAA Journal, Vol. 33, No. 2, Feb. (1995).

4. Chung, J., and Cole, G. L., "Comparison of Compressor Face Boundary Conditions for Unsteady CFD Simulations of Supersonic Inlets," AIAA paper 95-2627, July (1995).

5. Paynter, G. C., "Response of a Two-Dimensional Cascade to an Upstream Disturbance," AIAA Journal, Vol. 35, No. 3 March (1997).

6. Paynter, G. C., Clark, L. T., and Cole, G. L.. "Modeling the Response from a Cascade to an Upstream Acoustic Disturbance," AIAA paper 98-0953, January 1998.
7. Paynter, G. C., "Modeling the Response from a Cascade to an Upstream Convective Velocity Disturbance," AlAA paper 98-3570, July (1998).

8. Hale, A. A., and Davis, M. W. Jr., "Dynamic Turbine Engine Compressor Code DYNTECC - Theory and Capabilities," AIAA Paper 92-3190, (1992).

9. Garrard, D., Davis, M. Jr., Wehofer, S., and Cole, G., "A One Dimensional, Time Dependent Inlet/Engine Numerical Simulation for Aircraft Propulsion Systems," ASME paper 97-GT-333, June, 1997.

10. Abdel-Fattah, A. M., "Response of a Turbofan Engine Compression System to Disturbed Inlet Conditions," Journal of Turbomachinery, Vol. 119 , (1997).

11. Numbers, K., and Hamed, A., "Development of a Coupled Inlet-Engine Dynamic Analysis Method." AIAA Paper 97-2880, July (1997).

12. Freund, D., Sajben, M. and J. W. Slater, "Compressor-Face Boundary Condition Experiment: Generation of Acoustic Pulses in Annular Ducts," AIAA Paper 96-2657, July (1996).

13. Freund, D., and Sajhen, M., "Reflection of Large Amplitude Pulses from an Axial Flow Compressor," AIAA Paper 97-2879, July (1997).

14. Chung, J., Slater, J. W., Suresh, A.. and Townsend. S. "NPARC v3.1 User's Guide," October (1997).

15. Hall, E. J., and Delaney, R. A., "ADPAC User's Manual,” NASA CR 195472, May (1996).

16. Slater, J. W., Freund, D., and Sajben, M., "Study of CFD Methods Applied to Rapidly Deforming Boundaries," AIAA Paper 97-2041, June (1997).

17. "VCE Reference Manual," Version 2.6, CFD Research Corporation, October (1997).

18. Woodward, P., and Colella, P., "The Numerical Simulation of Two Dimensional Fluid Flow with Strong Shocks," J. Comput. Phys., Vol. 54, 115 ( 1984).

19. Freund, D. D., "Experimental Exploration of Compressor-Face Boundary Conditions for Unsteady Inlet Flow Computations," Ph.D. dissertation. University of Cincinnati, (1997). 


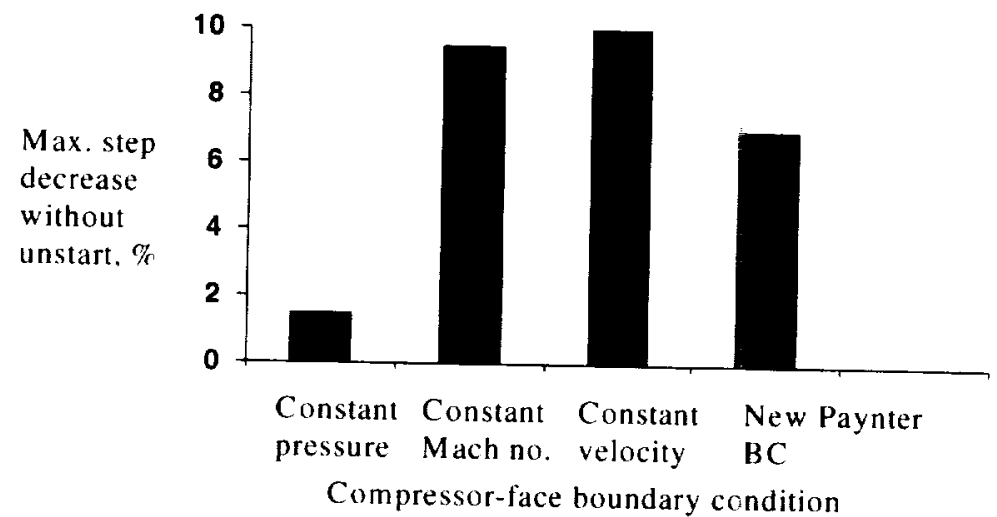

Fig. 1. Mixed-compression inlet unstart tolerance to step decrease in free-stream static pressure for various inlet-exit (compressor-face) boundary conditions.

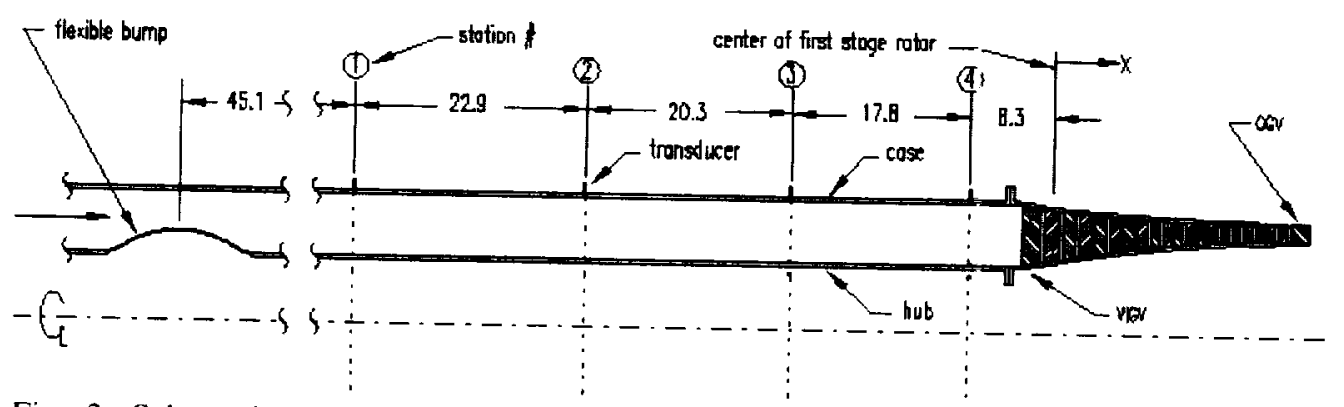
Fig. 2. Schematic of $\mathrm{U}$. of Cincinnati inlet-engine acoustic pulse experiment and pressure sensor locations
(dimensions in $\mathrm{cm}$ ). 


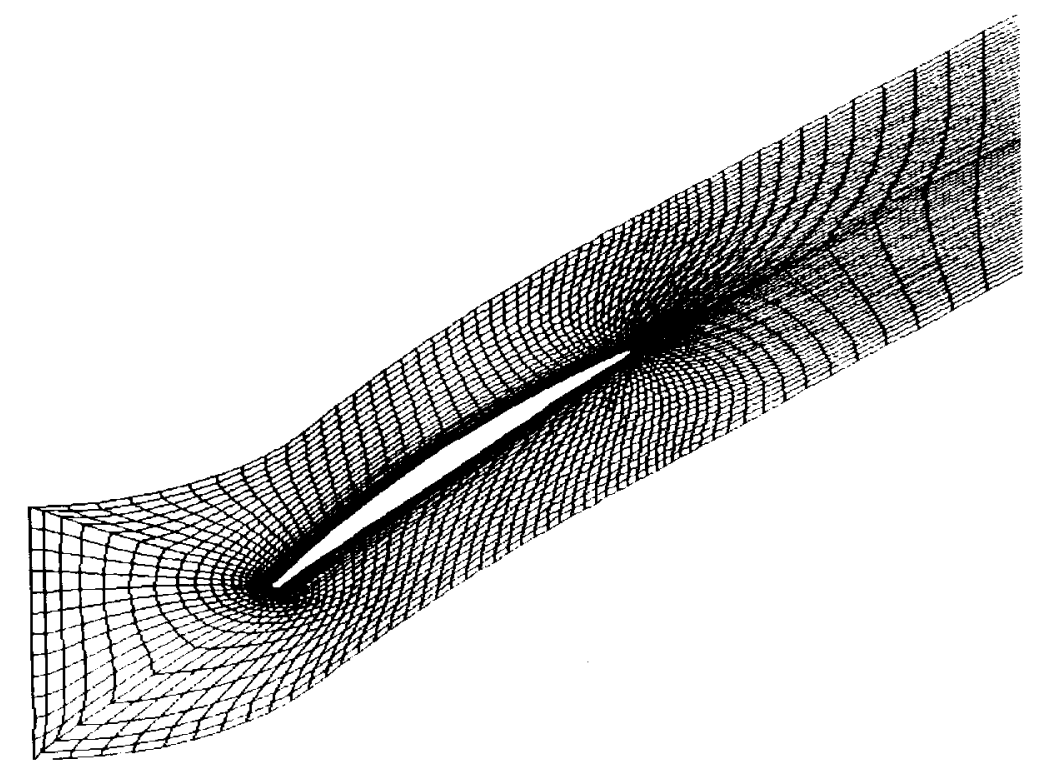

Fig. 3. Mid-span grid $(128 \times 33 \times 33)$ used in the ADPAC rotor simulation.

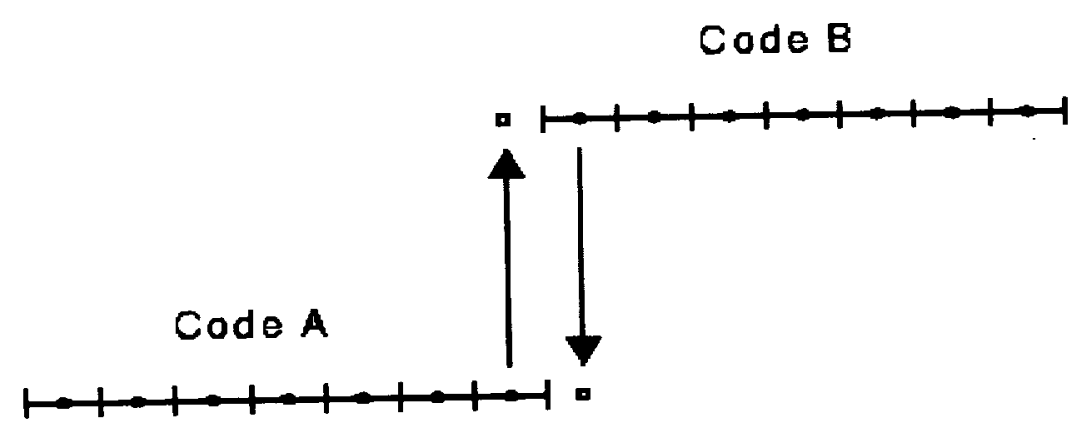

Fig. 4. Basic multi-block method used to couple two finite volume codes.

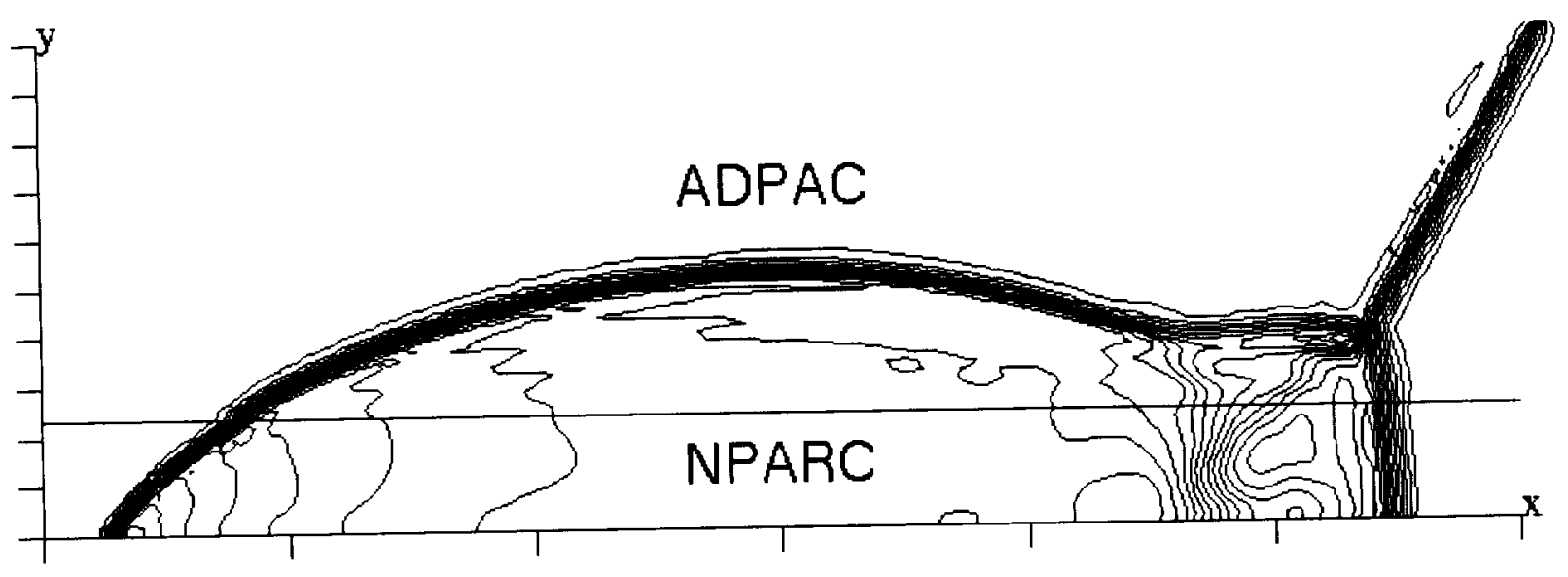

Fig. 5. Coupled NPARC-ADPAC solution for double Mach reflection problem, $\mathrm{CFL}=0.4,240 \times 60$ grid. Thirty density contours from 1.73 to 21 . 


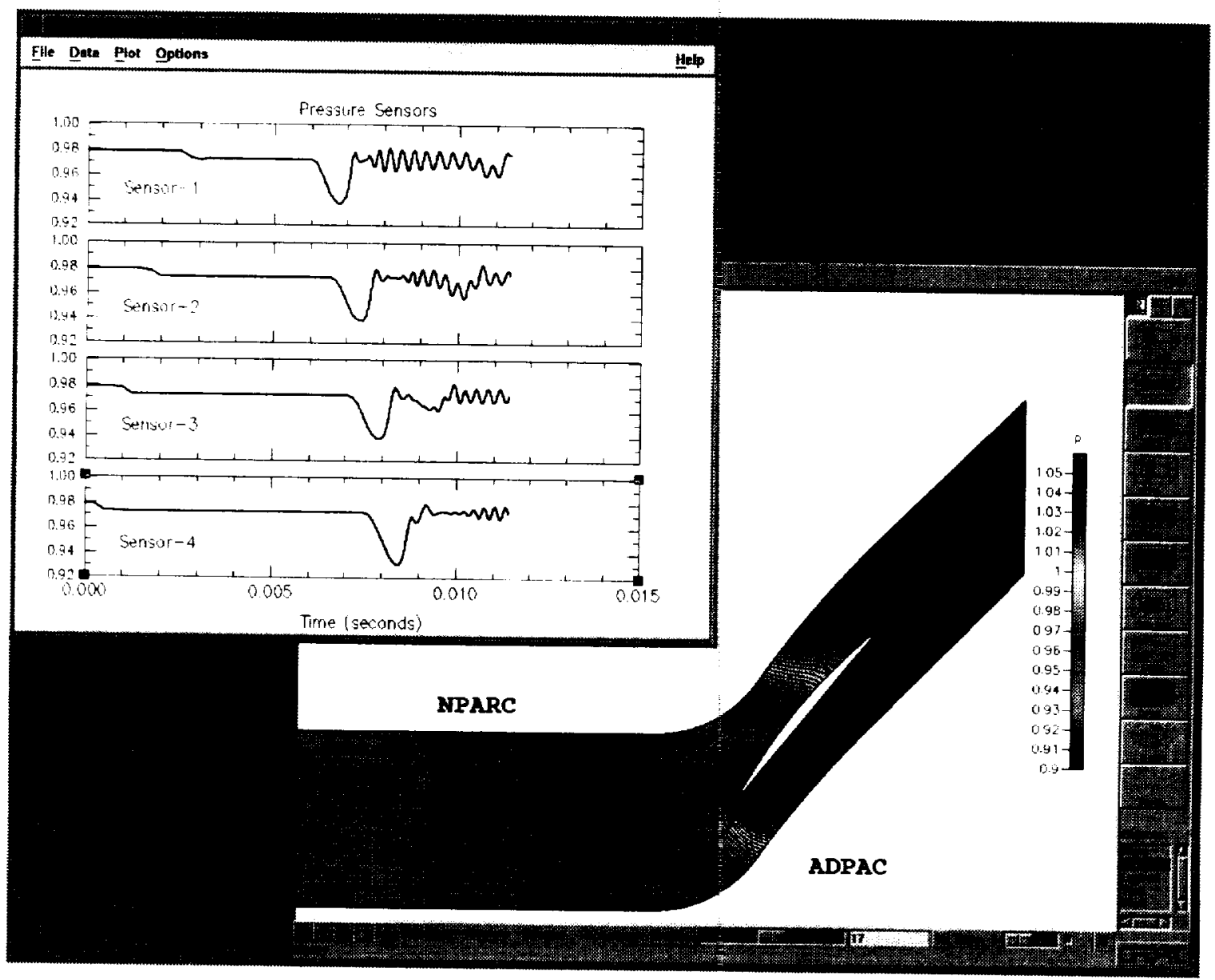

Fig. 6. Typical view of monitor screen during inlet-engine simulation. 


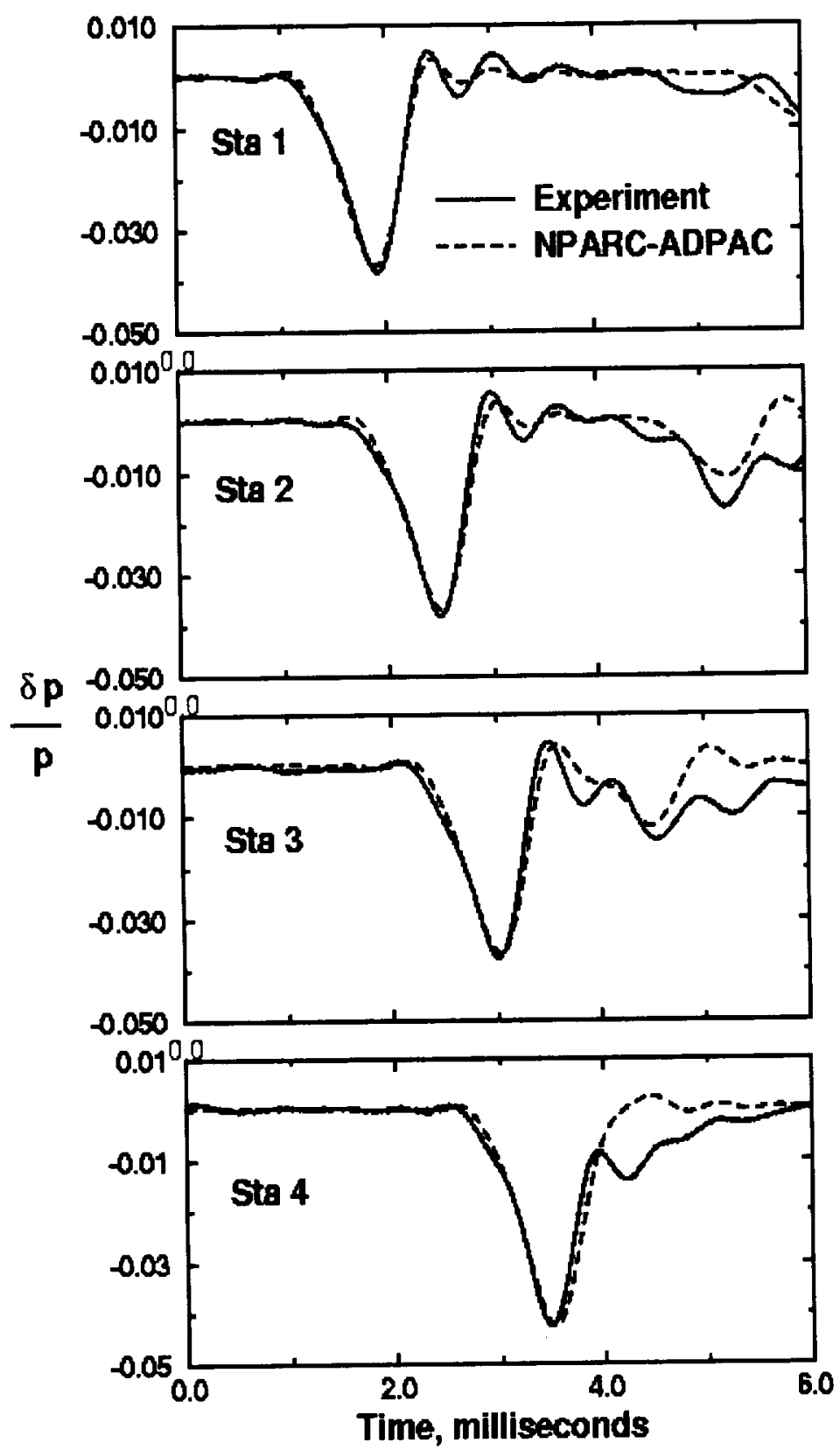

Fig. 7. Comparison of coupled NPARC-ADPAC solution with experimental results. 


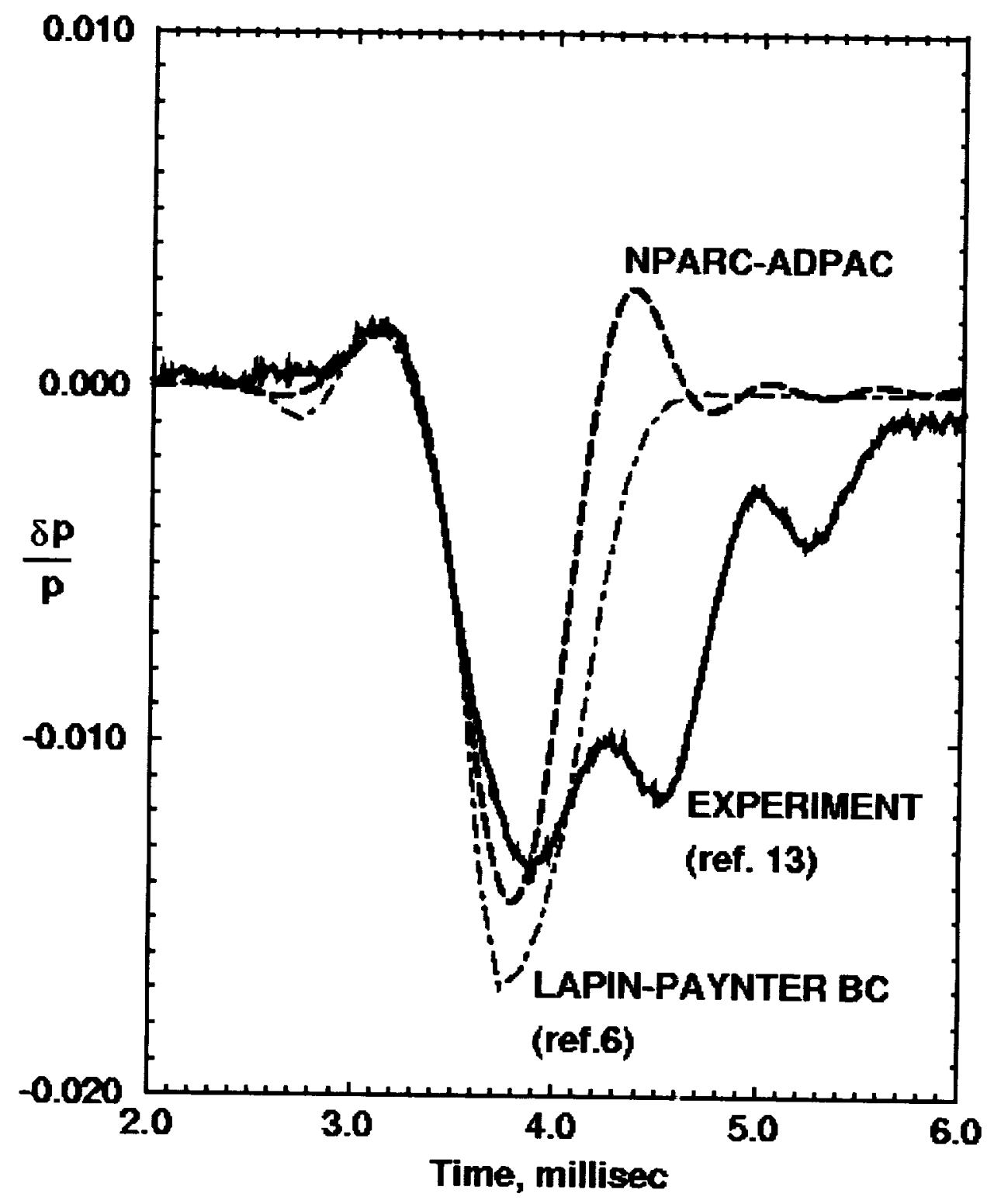

Fig. 8. Comparison of reflected wave from two simulations with experimental results. 
Public reporting burden for this collection of information is estimated to average 1 hour per response, including the time for reviewing instructions, searching existing data sources gathering and maintaining the data needed, and completing and reviewing the collection of information. Send comments regarding this burden estimate or any other aspect of this collection of information, including suggestions for reducing this burden, 10 Washington Headquarters Services, Directorate for Information Operations and Reponts, 1215 Jefferson Davis Highway. Suite 1204, A flington, VA 22202-4302, and to the Otfice of Management and Budgel, Paperwork Reduction Project (0704-0188). Washington. DC 20503.

\begin{tabular}{|l|c|c|}
\hline 1. AGENCY USE ONLY (Leave blank) & $\begin{array}{c}\text { 2. AEPORT DATE } \\
\text { December } 1998\end{array}$ & $\begin{array}{r}\text { 3. REPORT TYPE AND DATES COVERED } \\
\text { Technical Memorandum }\end{array}$ \\
\hline
\end{tabular}

\begin{tabular}{|l|l|l|}
\hline 4. TITLE AND SUBTITLE & 5. FUNDING NUMBERS
\end{tabular}

Analysis of Inlet-Compressor Acoustic Interactions Using Coupled CFD Codes

6. AUTHOR(S)

WU-509-10-11-00

A. Suresh, S.E. Townsend, G.L. Cole, J.W. Slater, and R. Chima

7. PERFORMING ORGANIZATION NAME(S) AND ADDRESS(ES)

National Aeronautics and Space Administration

Lewis Research Center

Cleveland, Ohio 44135-3191

8. PERFORMING ORGANIZATION

REPORT NUMBER

$E-11451$

9. SPONSORING/MONITORING AGENCY NAME(S) AND ADDRESS(ES)

10. SPONSORING/MONITORING AGENCY REPORT NUMBER

National Aeronautics and Space Administration

Washington, DC 20546-000I

NASA TM-1998-208839

AIAA-98-0749

\section{SUPPLEMENTARY NOTES}

Prepared for the 37th Aerospace Sciences Meeting \& Exhibit sponsored by the American Institute of Aeronautics and Astronautics. Reno, Nevada. January 11-14, 1999. A. Suresh. and S.E. Townsend (work funded under NAS3-98008), Dynacs Engineering, Inc.. 2001 Aerospace Parkwary. Brook Park. Ohio 44142: G.L. Cole. J.W. Slater. and R. Chima. NASA Lewis Research Center. Responsible person. G.L. Cole, organization code 5880. (216) 433-3655. Funding for this work provided by the NASA High-Performance Computing and Communications (HPCC) Program

\begin{tabular}{|l|l|l|l|}
\hline 12a. DISTRIBUTION/AVAILABILITY STATEMENT & 12b. DISTRIBUTION CODE
\end{tabular}

Unclassified - Unlimited

Subject Categories: 01 and 07

Distribution: Nonstandard

This publication is available from the NASA Center for AeroSpace Information. (301) 621-0390.

13. ABSTRACT (Maximum 200 words)

A problem that arises in the numerical simulation of supersonic inlets is the lack of a suitable boundary condition at the engine face. In this paper, a coupled approach, in which the inlet computation is coupled dynamically to a turbomachinery computation, is proposed as a means to overcome this problem. The specific application chosen for validation of this approach is the collapsing bump experiment performed at the University of Cincinnati. The computed results are found to be in reasonable agreement with experimental results. The coupled simulation results could also be used to aid development of a simplified boundary condition.

\section{SUBJECT TERMS}

Computational fluid dynamics: Unsteady flow; Inlets; Compressors; Interactions 15. NUMBER OF PAGES

SECURITY CLASSIFICATION OF REPORT

Unclassified
18. SECURITY CLASSIFICATION OF THIS PAGE

Unclassified
9. SECURITY CLASSIFICATION OF ABSTRACT

Unclassified 
